\title{
Mikoriza uygulaması ve farklı sulama seviyelerinin geç dönemde yetiştirilen hıyarın verim ve verim bileşenleri üzerine etkisi
}

\section{Effect of mycorrhiza application and different irrigation level on yield and yield components of cucumber grown in late period}

\author{
Sabri AKIN ${ }^{1 * i D}$, Mehmet ŞiMŞEK ${ }^{2}$ iD, Ali SARIOĞLU ${ }^{3}$ iD, Ali Demir KESKINER ${ }^{1}$ \\ ${ }^{1}$ Harran Üniversitesi, Ziraat Fakültesi, Tarımsal Yapılar ve Sulama Bölümü, Şanlıurfa \\ ${ }^{2}$ Şırnak Üniversitesi, Mühendislik Fakültesi, İnşaat Mühendisliği Bölümü, Şırnak \\ ${ }^{3}$ Harran Üniversitesi, Ziraat Fakültesi, Toprak Bilimi ve Bitki Besleme Bölümü, Şanlıurfa
}

\section{To cite this article:}

Akın, S., Şimşek, M., Sarıoglu, A. \& Keskiner, A.D. (2020). Mikoriza uygulaması ve farklı sulama seviyelerinin geç dönemde yetiştirilen hıyarın verim ve verim bileşenleri üzerine etkisi. Harran Tarım ve Gıda Bilimleri Dergisi, 24(2): 241249.

DOI: $10.29050 /$ harranziraat.660670

Address for Correspondence: Sabri AKIN

e-mail:

sabriakin@harran.edu.tr

Received Date:

17.12.2019

Accepted Date:

15.05.2020

\section{öz}

Mikoriza kök mantarı olarak adlandırılmakta ve kök korteksi içinde kolonize olarak çok sayıda lif üretmektedir. Üretilen bu lifler ile kök yüzey alanı genişlemekte ve bitkinin normalde alamayacağı uzaklıktaki su ve besin elementlerini alarak bitkiye ulaştırmaktadır. Bu çalışmanın amacı, mikoriza uygulamasının farklı sulama seviyelerinde hıyar bitkisinin verim ve verim bileşenleri üzerine etkisinin belirlenmesidir. Şanlıurfa ilinde 2017 yılı geç dönemde (ağustosekim) yürütülen bu araştırma, tesadüf blokları bölünmüş parseller deneme desenine göre 3 tekerrürlü olacak şekilde kurulmuştur. Ana parsel mikoriza uygulaması, alt parseller ise sulama suyu seviyelerinden ( $\mathrm{K}_{\mathrm{cp} 1}: 0.66, \mathrm{~K}_{\mathrm{cp2} 2}: 1.00$ ve $\left.\mathrm{K}_{\mathrm{cp} 3}: 1.33\right)$ olmuştur. Sulama suyu miktarı $A$ sınıf buharlaşma kabına göre hesaplanmış ve damla sulama yöntemi ile parsellere uygulanmıştır. Araştırmadan elde edilen sonuçlara göre, hıyar bitkisine güz dönemde uygulanan sulama suyu miktarı 334-673 mm, bitki su tüketim değerleri ise 379-685 mm arasında değişmiştir. Hıyar bitkisinin verimi $20.54 \mathrm{t} \mathrm{ha}^{-1}$ ile $33.66 \mathrm{t} \mathrm{ha}^{-1}$ arasında gerçekleşmiştir. En yüksek verim mikoriza uygulamasının yapıldığı ve sulama suyu ihtiyacının \%133'ünün karşılandığı konudan elde edilmiştir. Meyve çapı, meyve boyu ve meyve ağılığı değerleri; sırasıyla 29-36 mm, 134-161 mm ve 103-135 g arasında ölçülmüştür. Çalışma sonucunda, mikoriza ve sulama uygulamasının hıyar bitkisinin verim ve verim parametreleri üzerinde önemli bir etkiye sahip olduğu tespit edilmiştir.

\section{Anahtar Kelimeler: Yarı kurak, Su verim ilişkisi, Damla sulama}

\section{ABSTRACT}

Mycorrhiza is called root fungus and produces many fibers colonized within the root cortex. With these fibers produced, the root surface area expands and delivers to the plant by taking water and nutrients from the distance that the plant would not normally receive. This study aimed to investigate the effect of the mycorrhiza application on yield and yield components of cucumber plant at different irrigation levels. The design of the experiment was established with randomized blocks design with three replicates in Şanlıurfa province in the late season (august-october 2017). The main parcel was the mycorrhiza application and the lower parcels were irrigation water levels ( $\mathrm{K}_{\mathrm{cp} 1}: 0.66, \mathrm{~K}_{\mathrm{cp} 2}: 1.00$ ve $\left.\mathrm{K}_{\mathrm{cp} 3}: 1.33\right)$. Irrigation water amount was calculated according to class $A$ evaporation pan and applied by drip irrigation method. According to the results obtained from the research, the amount of irrigation water given to the cucumber plant in the period of the fall season was $334-673 \mathrm{~mm}$, and the seasonal evapotranspiration values ranged from $379-685 \mathrm{~mm}$. The yield of cucumber was ranged between $20.54 \mathrm{t} \mathrm{ha}^{-1}$ and $33.66 \mathrm{t} \mathrm{ha}^{-1}$. The highest yield was obtained from the mycorrhiza application and $133 \%$ of irrigation water requirement was met. Fruit diameter, fruit size, and fruit weight values were measured between $29-36 \mathrm{~mm}, 134-161 \mathrm{~mm}$, and 103-135 g respectively. As a result of the study, it was determined that the application of the mycorrhiza and irrigation had a significant effect on yield and yield parameters of cucumber.

Key Words: Semiarid, Water yield relationship, Drip irrigation
(C) Copyright 2018 by Harran University Faculty of Agriculture. Available on-line at www.dergipark.gov.tr/harranziraat Non Commercial 40 


\section{Giriş}

Bitkisel üretimde kuraklık gibi iklimsel faktörlerin yarattığı abiyotik stres koşulları, verimde farklı tepkilere neden olmaktadır (Jones ve Carlott, 1992; Lizana ve ark., 2006). Abiyotik stres koşullarının oluşumunun başında sıcaklık, nispi nem, radyasyon, yağış ve rüzgâr gibi faktörler gelmektedir (Ment ve ark., 2017). Sıcaklığın ve buharlaşmanın artmasıyla ve buna bağlı olarak düşük nispi nem koşulları, yoğun su sıkıntısı yaşanmasına ve toprakta ciddi nem azalışları meydana gelmesine, sonuç olarak bitkisel üretimde verim kaybına neden olmaktadır. Sıcaklık ve su, bitkisel üretim için iki önemli faktördür. Dünyada ve ülkemizde tatlı-su kaynakları oldukça sınırlıdır. Sektörel su dağılımında kişi başı su tahsisi 1 000-2 $000 \mathrm{~m}^{3} \mathrm{yıl}^{-1}$ olan ülkeler su sıkıntısı çeken ülkeler kategorisinde yer almaktadır. Ülkemiz için bu durum incelendiğinde; 2017 yılı kişi başı su arzının $1400 \mathrm{~m}^{3}$ olduğu ve Türkiye'nin su sıkıntısı çeken ülkeler arasında yer aldığı bildirilmektedir (Anonim, 2017a). Ülkelerin demografik yapılarındaki artış trendine paralel olarak yakın gelecekte, suyunda bir kısıt faktörü olacağı sinyali şimdiden kendisini hissettirmektedir. Bu nedenle, tüm doğal kaynakların rasyonel kullanılmasının yukarıda açıklanan gerekçelerden dolayı zorunlu olduğu görülmektedir. Toprak-bitki-su ilişkisi bakımından bitkisel üretimde ciddi tehlike yaratan en büyük doğal afetlerden birisi kuraklıktır. Bitkisel üretimde kuraklık stresinin diğer abiyotik streslerden daha yıkıcı etkisi bulunmaktadır (Lambers ve ark., 2008). Böyle durumlarda; suyun etkin kullanılması ve bitki yetişme dönemlerinin pik olduğu günlerde, sudan optimum faydanın sağlanması amaçlanmaktadır. Çünkü, su stresi altında olan bitkinin metabolik ve fizyolojik özelliklerine bağı olarak, bitkinin farklı dönemlerindeki tepkileri de farklılık göstermektedir. Örneğin, 28 yıl süren bir buğday çalışmasında kurak dönemlerde; organik madde ve $\mathrm{N}$ içeriklerinin önemli ölçüde arttığı, buhar basıncı açığının ve potansiyel evapotranspirasyonun (ETo) yükseldiği, ayrıca mevsimsel yağış miktarının azaldığı görülmüştür (Zhang ve ark., 2017). Diğer yandan dünyada birçok alanın kuraklık ve tuzluluk stresinden etkilendiği ve bu alanlarında giderek arttığı bildirilmektedir (Wang ve ark., 2003). Kuraklığın bitki gelişimini bu denli olumsuz etkilemesi hem ekolojik anlamda hem de suyun kısıtlı kullanılması gerekliliğini doğurmuştur. Bu aşamada bitkilerle simbiyotik yaşam süren arbüsküler mikoriza fungusları bitkisel üretimde önemli rol oynamaktadır. Arbüsküler mikoriza, özellikle fosfor gibi toprakta hareketsiz bulunan bitki besin elementlerinin alımında yardımcı olurlar (Marschner ve Dell, 1994; Al-Karaki ve AlRaddad,1997; Al-Karaki, 2006). Bitki köklerindeki fungaller simbiyotik kök yüzey alanlarının artmasına neden olurlar. Böylece, ağır bünyeli topraklarda bitki için daha etkili beslenmeye ve su alımına olanak sağlanır. Mikorizal bileşimler bitki besleme seviyelerini ve kullanılabilir nem düzeylerini sadece artırmadığı gibi, ayrıca bitkiyi farklı abiyotik streslerden koruduğu da bildirilmektedir (Evelin ve ark., 2009; Miransari, 2010). Nitekim kökler su stres algısının habercisidir. Sulama konuları ve bitki besleme, bitki kök yoğunluğunda önemli birer faktördür. Köklerdeki havalandırma ile su ve bitki besleme fonksiyonları artar (Kramer ve Boyer, 1995). Birçok kaynak rizobakteri ve mikorizanın stres koşullarında yetiştiriciliği yapılan bitkinin gelişiminde önemli bir role sahip olduğunu bildirir (Nadeem ve ark., 2014). Özellikle hıyar bitkisi gibi suya duyarlılığın fazla olduğu bitkilerde rizobakteri ve mikoriza uygulamalarının yapılması verim ve kalitede önemli katkılar ortaya çıkarabilir. Hıyar meyve verimleri, toplam büyüme döneminde su stresi yaşanan sulama uygulamalarından ciddi oranda etkilendiği bildirilmiştir (Mao ve ark., 2003). Ülkemizde 2005-2017 yılları arasında yıllık ortalama 1622789 ton hıyar üretimi gerçekleştirilmiştir (Anonim, 2017b). Kabakgiller familyasından olan hıyar bitkisinin meyvesi $\mathrm{C}$ vitamini bakımından zengin olup, önemli bir antioksidandır (Dhillon ve ark., 2012). Çiğ tüketilen hıyar bitkisinde mikoriza uygulaması ile kısıtlı su uygulamaları birlikte yürütülmesi halinde 
verim ve verim bileşenlerinde önemli sonuçlara neden olacağı, çalışmanın ana fikrini oluşturmuştur. Bu hipotez ile hıyar bitkisinde mikoriza ve farklı sulama suyu seviyelerinin verim ve kalite üzerine etkileri saptanmıştır.

\section{Materyal ve Metot}

Araştırma, 2017 yılında Harran Üniversitesi Ziraat Fakültesi AR-GE çalışma alanında ağustos ve ekim ayları arasında yürütülmüştür. Araştırma alanı toprakları Harran Ovası topraklarının özelliklerini karakterize etmektedir. Topraklar, profil boyunca kil ve kireç içermekte, organik madde miktarı yüzeyden aşağılara inildikçe azalmakta, katyon değişim kapasiteleri ise yüksek kil içeriği nedeniyle artmaktadır. Harran Ovası toprakları tüm profil boyunca genellikle ağır bünyeli olup, I. ve II. sınıf araziler olarak değerlendirilmektedir (Dinç ve ark., 1988). Araştırma alanı topraklarının bazı fiziksel ve kimyasal özellikleri Çizelge $1^{\prime}$ de verilmiştir. Çalışma sonucunda hıyar bitkisinin mevsimlik su tüketimi hesabında ve bitkinin yaşam süresi boyunca, etkili kök bölgesinin nem değişimlerinin belirlenmesinde topraklarının $0-60 \mathrm{~cm}$ derinliği dikkate alınmıştır.

Çizelge 1. Araştırma alanı topraklarının bazı fiziksel ve kimyasal özellikleri

Table 1. Some properties of research area soils

\begin{tabular}{|c|c|c|c|c|c|c|c|c|c|c|}
\hline $\begin{array}{c}D \\
(\mathrm{~cm})\end{array}$ & $\begin{array}{c}\text { TK } \\
\left(\mathrm{g} 100 \mathrm{~g}^{-1}\right)\end{array}$ & $\begin{array}{c}\text { SN } \\
\left(g_{\left.100 g^{-1}\right)}\right.\end{array}$ & $\begin{array}{c}\rho \\
\left(\mathrm{g} \mathrm{cm}^{-3}\right)\end{array}$ & $\begin{array}{c}\text { Kum } \\
\text { Sand } \\
(\%)\end{array}$ & $\begin{array}{c}\text { Kil } \\
\text { Clay } \\
(\%)\end{array}$ & $\begin{array}{l}\text { Silt } \\
\text { Silt } \\
(\%)\end{array}$ & $\mathrm{pH}$ & $\begin{array}{c}\mathrm{EC} \\
\left(\mathrm{dS} \mathrm{m}^{-1}\right)\end{array}$ & $\begin{array}{c}\text { Org. } \\
\text { Madde } \\
\text { Org. } \\
\text { Matter } \\
\text { (\%) }\end{array}$ & $\begin{array}{c}\text { Kireç } \\
\text { Lime } \\
(\%)\end{array}$ \\
\hline $0-30$ & 28.04 & 16.74 & 1.37 & 20.40 & 54.00 & 25.60 & 7.85 & 0.67 & 2.33 & 7.90 \\
\hline $30-60$ & 28.82 & 17.35 & 1.39 & 20.40 & 52.00 & 27.60 & 7.94 & 0.59 & 1.31 & 9.50 \\
\hline
\end{tabular}

TK: tarla Kapasitesi, SN: solma noktası, D: derinlik, $\rho:$ hacim ağırlığı

TK: field capacity, SN: permenant wilting point, D: depth, $\rho$ : bulk density

Araştırma, bölünmüş parseller deneme desenine göre 3 tekerrürlü olarak yürütülmüştür. Hıyar tohumu için Erciyes $F_{1}$ çeşidi kullanılmıştır. Kullanılan çeşit, erkenci olup açık tarla koşullarında bahar ve güz dönemlerinde yetiştiriciliği yapılabildiği bildirilmektedir (Anonim, 2019). Araştırmanın tarla koşullarında ve mevsimin güz döneminde olması nedeniyle, Erciyes $F_{1}$ çeşidi kullanılması tercih nedeni olmuştur. Hıyar tohumları dar sıra arası $50 \mathrm{~cm}$, geniş sıra arası $250 \mathrm{~cm}$ ve sıra üzeri $35 \mathrm{~cm}$ olacak şekilde 04.08.2017 tarihinde ekilmiştir. Toprak kültürel işlemleri 01 Ağustos 2017 tarihinde başlanmıştır. Ekim öncesi 30 kg da-1 20-20-0 NPK, bir ay sonra (04.09.2017) $10 \mathrm{~kg} \mathrm{da}^{-1} \mathrm{P}_{2} \mathrm{O}_{5}$, bir hafta sonra (12.09.2017) $12 \mathrm{~kg} \mathrm{da}^{-1} \mathrm{~K}_{2} \mathrm{O}_{5}$ ve dört gün sonra $3 \mathrm{~kg} \mathrm{da}^{-1} \mathrm{CaO}$ gübreleri, gübre tankından uygulanmıştır. Emici böceklerle iki kez farklı tarihte 3 hafta arayla [beyaz sinek (Bemisia tabaci) ve kırmızı örümcek (Tetranychus urticae) için] mücadele yapılmıştır. Araştırma alanının sulama suyu ihtiyacı üniversite AR-GE alanından geçen sulama kanalından pompa ile 500 tonluk sulama deposuna alındıktan sonra deneme alanına $\varnothing 75^{\prime}$ lik PE ana boru ile taşınmıştır. Bitkilerin sulanmasında damla sulama sistemi kullanılmıştır. Bu sistemde; $\varnothing 32$ manifold, $\varnothing 16$ lateral borular, damlatıcı aralığı $40 \mathrm{~cm}$ ve $150 \mathrm{kPa}$ işletme basıncında damlatıcı debisi $4 \quad \mathrm{I}^{-1}$ kullanıımıştır. Çalışma alanında kullanılan suların Sodyum Adsorbsiyon Oranı (SAR:S) ve Elektriksel Iletkenlik [(EC:C ( $\mu$ mhos $\left.\mathrm{cm}^{-1}\right)$ ] değerleri suların hangi sınıfta olduğunu göstermektedir. Elde edilen bulgular sulama sularının $\mathrm{C}_{2} \mathrm{~S}_{1}$ orta tuzlu-az sodyumlu sular olduğunu bildirmektedir. Araştırma alanının bulunduğu Şanlıurfa ilinde yazlar sıcak ve kurak, kışlar ise soğuk ve az yağışlı geçmektedir. Uzun yıllar iklim verilerine göre yıllık yağış miktarı $456 \mathrm{~mm}$, sıcaklıklar ise $-12.4{ }^{\circ} \mathrm{C}$ ile $45.8{ }^{\circ} \mathrm{C}$ arasında değişmektedir. Coğrafi koordinatlar ve yaşanan iklim değerleri, araştırma alanının yarı-kurak iklim kuşağı etkisi altında 
olduğunu işaret etmektedir. Çizelge 2'den izleneceği gibi; sıcaklık, nispi nem, buharlaşma ve yağış değerlerine ait dağılımlar aylara göre büyük farklııklar göstermiştir. En sıcak ayın temmuz, en düşük sıcaklıkların ocakta gerçekleştiği saptanmıştır. Bu nedenle erkenci ve geçci yazlık bir sebze olan hıyar bitkisinde, optimum koşullar yaratmak için, geç yaz döneminde ekilen bitkide sulama programlarının uygulanması zorunluluk göstermiştir. Nitekim nispi nemin düşük olduğu, sıcaklığın çok yüksek gerçekleştiği temmuz ve ağustos aylarında su tüketimlerinin doğrusal olarak arttığı gözlemlenmiştir (Anonim, 2018).

Çizelge 2. Şanlıurfa ilinin iklim verileri

Table 2. Climate date of Şanlıurfa province

\begin{tabular}{|c|c|c|c|c|c|c|}
\hline \multirow{2}{*}{$\begin{array}{l}\text { Parametreler } \\
\text { Parameters }\end{array}$} & \multicolumn{2}{|c|}{$\begin{array}{l}\text { Ağustos } \\
\text { August }\end{array}$} & \multicolumn{2}{|c|}{$\begin{array}{c}\text { Eylül } \\
\text { September }\end{array}$} & \multicolumn{2}{|c|}{$\begin{array}{c}\text { Ekim } \\
\text { October }\end{array}$} \\
\hline & $\begin{array}{c}\text { Uz. Yıl } \\
\text { Long Year }\end{array}$ & 2017 & $\begin{array}{c}\text { Uz. YIl } \\
\text { Long Year }\end{array}$ & 2017 & $\begin{array}{c}\text { Uz. Yıl } \\
\text { Long Year }\end{array}$ & 2017 \\
\hline $\begin{array}{l}\text { Ortalama sıcaklık }\left({ }^{\circ} \mathrm{C}\right) \\
\text { Average temperature }\left({ }^{\circ} \mathrm{C}\right)\end{array}$ & 31.5 & 32.2 & 27.1 & 29.6 & 20.5 & 20.5 \\
\hline $\begin{array}{l}\text { Ortalama nisbi nem (\%) } \\
\text { Average relative humidity (\%) }\end{array}$ & 32.1 & 35.7 & 35.1 & 28.8 & 44.4 & 36.9 \\
\hline $\begin{array}{l}\text { Toplam yağış }\left(\mathrm{kg} \mathrm{m}^{-2}\right) \\
\text { Total rainfall }\left(\mathrm{kg} \mathrm{m}^{-2}\right) \\
\end{array}$ & 3.3 & 0.0 & 4.7 & 0.0 & 26.1 & 17.1 \\
\hline $\begin{array}{l}\text { Ortalama buhar basıncı (mb) } \\
\text { Average steam pressure }(\mathrm{mb})\end{array}$ & 12.8 & 15.8 & 11.0 & 11.0 & 9.4 & 8.1 \\
\hline $\begin{array}{l}\text { Güneş süresi (saat) } \\
\text { Sun time (hour) } \\
\end{array}$ & 11.4 & 10.9 & 10.0 & 9.6 & 7.9 & 8.6 \\
\hline $\begin{array}{l}\text { Ortalama rüzgâr hızı }\left(\mathrm{m} \mathrm{s}^{-1}\right) \\
\text { Average wind speed }\left(\mathrm{m} \mathrm{s}^{-1}\right)\end{array}$ & 2.5 & 1.6 & 2.2 & 1.4 & 1.6 & 1.3 \\
\hline
\end{tabular}

Çalışmada, ana parsel mikorizasız (Mo) ve mikorizalı (M), alt parseller 3 farklı sulama suyu düzeyinden $\left(I_{1}, I_{2}\right.$ ve $\left.I_{3}\right)$ oluşmuştur. Ana parsel olan mikoriza uygulaması $250 \mathrm{~g} \mathrm{da}^{-1}$ olacak şekilde klorsuz su kullanılarak 14.08.2017 tarihinde bitki köklerine damla sulama sistemi ile uygulanmıştır. Mikoriza olarak Arbusculer mikoriza fungus [Arbuscular Mycorrhizal Fungi (AMF)] kullanılmış olup mikoriza içeriğinde Glomus intraradices, Glomus aggregatum, Glomus mosseae, Glomus clarum, Glomus monosporus, Glomus deserticola, Glomus brasilianum, Glomus etunicatum, Gigaspora margarita bulunmaktadır. Araştırma boyunca mevsimlik bitki su tüketim hesaplamalarında kullanılmak üzere hıyar bitkisinde konulu sulama başlamadan önce ve son hasadın yapıldığı dönemde; $0-30$ ve $30-60 \mathrm{~cm}$ toprak derinliğinden bozulmuş numuneler alınmıştır. Alınan toprak örnekleri, $105{ }^{\circ} C^{\prime} y e$ ayarlanan etüvde 24 saat bekletildikten sonra toprakların nem tayinleri saptanmıştır. Böylece bozulmuş toprak numunelerinin nem içerikleri gravimetrik yöntemle tayin edilmiş ve toprakların vertikal seviyelerinin nem düzeylerindeki azalış ve artışlar saptanmıştır. Sulama düzeyleri; class A pan buharlaşma leğeninde oluşan, açık su yüzeyi buharlaşmasının dört günlük su derinliklerinin; $l_{1}$ : \%66 (K $\left.K_{\mathrm{cp}}: 0.66\right)^{\prime} \operatorname{sının,~} \mathrm{I}_{2}$ : \%100 ( $\left.K_{\mathrm{cp}}: 1.00\right)$ 'ünün ve I3: \%133 ( $\left.K_{\mathrm{cp}}: 1.33\right)^{\prime}$ ünün uygulandığı 3 farklı su seviyesi kullanılmış ve hacimsel su $\left(\mathrm{m}^{3}\right)$ miktarları su sayacında denetlenerek konulara uygulanmıştır. Çalışmada uygulanacak sulama suyu miktarı aşağıda verilen Eşitlik 1'e göre belirlenmiştir (Doorenbos ve Pruitt, 1977). Eşiklikte verilen bitki örtü yüzdesi tüm parseller için 1.00 şeklinde kullanılmıştır. Örtü yüzdesi dar sıra geniş sıra yaklaşımına bağlı kalınarak bir metre kabul edilmiştir.

$I=A * \Sigma E_{p} * K_{c p} * P$

I: Parsele uygulanan sulama suyu miktarı (litre), A: parsel alanı $\left(\mathrm{m}^{2}\right), E_{p}$ : sulama aralığındaki toplam class A pandaki buharlaşma miktarı $(\mathrm{mm}), \mathrm{K}_{\mathrm{cp}}$ : bitki pan katsayısı, P: örtü yüzdesi (\%).

Araştırmadaki konulara ilişkin bitki su tüketim değerleri aşağıda verilen Eşitlik 2'ye göre hesaplanmıştır (James ve ark., 1982). 
$E T=I+P_{r}+C_{r}-D_{p}+R_{f} \pm \Delta S$

ET: Gerçek bitki su tüketimi $(\mathrm{mm})$, I: uygulanan sulama suyu miktarı $(\mathrm{mm})$, Pr: etkili yağış $(\mathrm{mm})$, $C_{r}$ : kapilar yükselme $(\mathrm{mm}), \mathrm{D}_{\mathrm{p}}$ : derine sızma $(\mathrm{mm})$, $\mathrm{R}_{\mathrm{f}}$ : yüzey akış kayıpları $(\mathrm{mm}), \Delta \mathrm{S}$ : toprak profilindeki (kök bölgesinde) nem değişim miktarı ( $\pm \mathrm{mm}$ ). Çalışmada damla sulama yöntemi kullanıldığından $D_{p}$ ve $R_{f}$ gerçekleşmediği kabul edilmiştir.

Çalışmada su kullanım randımanı Eşitlik 3'e, sulama suyu kullanım etkinliği ise Eşitlik 4'e göre hesaplanmıştır (Howell ve ark., 1990).

$W U E=\frac{Y}{E T}$

WUE: Su kullanım randımanı $\left(\mathrm{kg} \mathrm{m}^{-3}\right), \mathrm{Y}$ : Verim ( $\mathrm{t}$ $\left.\mathrm{ha}^{-1}\right)$, ET: Mevsimlik bitki su tüketimi ( $\mathrm{mm}$ )

$I W U E=\frac{Y}{I W}$

IWUE: Sulama suyu kullanım randımanı, Y: Verim $\left(\mathrm{t} \mathrm{ha}^{-1}\right)$, IW: Uygulanan sulama suyu miktarı $(\mathrm{mm})$
Araştırma süresi boyunca incelenen parametreler sırasıyla; meyve uzunluğu meyvenin iki ucu arasındaki mesafe ve meyve çapı kumpas yardımı ile ölçülmüş, meyve ağırlığı hassas terazi ile ayrı ayrı tartılarak belirlenmiştir. Toplam verim; tüm parsellerden alınan meyvelerin ağırlığı, hasat sonrasında tartılmış ve 11 hasadın verim tayinleri yapılmıştır.

Araştırma sonucunda elde edilen verilerin varyans analizleri SPSS paket programı ile gerçekleştirilmiş, ortalamalar arası farklılıkları saptamak amacıyla TUKEY testinden yararlanılmış ve konuların standart sapmaya ait değerleri aynı çizelgede gösterilmiştir.

\section{Bulgular ve Tartışma}

Çalışma süresince konulara göre uygulanan sulama suyu miktarı (IW), mevsimlik su tüketimi miktarı (ET), su kullanım randımanı (WUE) ve sulama suyu kullanım randımanı (IWUE) Çizelge 3'te gösterilmiştir.

Çizelge 3. Hıyar bitkisinde sulama suyu $(\mathrm{mm})$, bitki su tüketimi $(\mathrm{mm})$, verim ( $\left.\mathrm{ha}^{-1}\right)$, su kullanım randımanı $\left(\mathrm{kg} \mathrm{m}^{-3}\right)$ ve sulama suyu kullanım randımanı $\left(\mathrm{kg} \mathrm{m}^{-3}\right)$

Table 3. Irrigation water $(\mathrm{mm})$, plant water consumption $(\mathrm{mm})$, yield $\left(\mathrm{t} \mathrm{ha} \mathrm{a}^{-1}\right)$, water use efficiency $\left(\mathrm{kg} \mathrm{m}^{-3}\right)$, and irrigation water use efficiency $\left(\mathrm{kg} \mathrm{m}^{-3}\right)$ in cucumber plant

\begin{tabular}{cccccc}
\hline $\begin{array}{c}\text { Konu } \\
\text { Treatment }\end{array}$ & $\begin{array}{c}\text { IW } \\
(\mathrm{mm})\end{array}$ & $\begin{array}{c}\text { ET } \\
(\mathrm{mm})\end{array}$ & $\begin{array}{c}\text { Y } \\
\left(\mathrm{t} \mathrm{ha}^{-1}\right)\end{array}$ & $\begin{array}{c}\text { IWUE } \\
\left(\mathrm{kg} \mathrm{m}^{-3}\right)\end{array}$ & $\begin{array}{c}\text { WUE } \\
\left(\mathrm{kg} \mathrm{m}^{-3}\right)\end{array}$ \\
\hline $\mathrm{M}_{0} \mathrm{I}_{1}$ & 334 & 378.59 & 20.54 & 6.15 & 5.42 \\
$\mathrm{M}_{0} \mathrm{I}_{2}$ & 506 & 530.51 & 26.94 & 5.32 & 5.08 \\
$\mathrm{M}_{0} \mathrm{I}_{3}$ & 673 & 685.04 & 32.12 & 4.77 & 4.69 \\
$\mathrm{M}-\mathrm{I}_{1}$ & 334 & 379.74 & 25.52 & 7.64 & 6.72 \\
$\mathrm{M}-\mathrm{I}_{2}$ & 506 & 539.40 & 30.96 & 6.12 & 5.74 \\
$\mathrm{M}-\mathrm{I}_{3}$ & 673 & 688.45 & 33.66 & 5.00 & 4.89 \\
\hline
\end{tabular}

IW: Sulama suyu, ET: Bitki su tüketimi, Y: Verim, IWUE: Sulama suyu kullanım randımanı, WUE: Su kullanım randımanı IW: Irrigation water, ET: Plant water consumption, Y: Yield, IWUE: Irrigation water use efficiency, WUE: Water use efficiency

Araştırma süresi boyunca hıyar bitkisine uygulanan 3 farklı sulama suyu seviyesi $\left(I_{1}, I_{2}\right.$ ve $\left.I_{3}\right)$ konularına uygulanan sulama suyu miktarı 334$673 \mathrm{~mm}$ arasında değişmiştir. Çalışma alanının yarı-kurak bölgede olmasına karşın, araştırmanın yapıldığı mevsim güz dönemine denk geldiğinden dolayı uygulanan sulama suyu miktarları, yaz mevsiminde yetiştiriciliği yapılan hıyar bitkisine göre daha düşük gerçekleşmiştir. Araştırmada, uygulanan en düşük sulama suyu miktarı su ihtiyacının \%66'sının karşılandığı l l konusunda 334 mm gerçekleşirken en yüksek sulama suyu miktarı ise su ihtiyacının \%133'nün karşılandığı $l_{3}$ konusunda $673 \mathrm{~mm}$ hesaplanmış ve uygulanmıştır. Aynı lokasyonda yaz mevsiminde yürütülmüş çalışmada hıyar bitkisinin su ihtiyacının tamamının karşılandığı (\%100) konuda $813 \mathrm{~mm}$ olarak belirlenmiştir (Şimşek ve ark., 2005). İki çalışma arasında uygulanan sulama suyu miktarlarının ekim zamanının farklılığından ve buna bağlı olarak mevsim şartlarından ileri geldiği söylenebilir. Güz döneminde yetiştirilen hıyar 
bitkisinin 3 farklı sulama suyu seviyesindeki bitki su tüketimleri 378.59-688.45 mm arasında değişmiş, bitki su tüketim değerlerinin uygulanan sulama suyu miktarları ile paralellik gösterdiği, en yüksek bitki su tüketimi mikorizanın uygulandığı $I_{3}$ konusunda $688.45 \mathrm{~mm}$ gerçekleşirken en düşük bitki su tüketimi ise mikorizanın uygulanmadığı $I_{1}$ konusunda $378.59 \mathrm{~mm}$ şeklinde saptanmıştır. Araştırmanın yürütüldüğü ekim ayının son günlerinde gerçekleşen $17 \mathrm{~mm}$ 'lik yağış, son hasattan sonra gerçekleştiği için bitki su tüketimi hesaplanmalarında dikkate alınmamıştır. Sulama suyu kullanım randımanı (IWUE) $5.00-7.64 \mathrm{~kg} \mathrm{~m}^{-3}$, su kullanım randımanı 4.69-6.72 $\mathrm{kg} \mathrm{m}^{-3}$ arasında değişmiştir. En yüksek IWUE ve WUE değerleri $\mathrm{M}-\mathrm{I}_{1}$ konusundan elde edilirken, en düşük değerler ise $\mathrm{M}_{0}-\mathrm{I}_{3}$ konusunda elde edilmiş ve bu sonuçlara göre mikoriza ve kısıtlı sulama suyu uygulanan konuda IWUE ve WUE değerlerinde önemli değişikliklerin elde edildiği saptanmıştır. Su kısıtı uygulanmayan ve tarla koşullarında yürütülen denemede, hıyar bitkisinin mevsimlik IW, ET, IWUE ve WUE değerleri sırasıyla $965 \mathrm{~mm}, 960 \mathrm{~mm}, 3.38 \mathrm{~kg} \mathrm{~m}^{-3}$ ve $3.40 \mathrm{~kg}$ $\mathrm{m}^{-3}$ olduğu bildirilmiştir (Kırnak ve Demirtaş, 2006). Tuz stresi altında hıyar yetiştirilen başka bir çalışmada ise WUE değerinin 4.06-6.65 kg ha-1 arasında elde edildiği tespit edilmiştir (Abd ElMageed ve ark., 2018). Mikoriza ( $M_{0}$ ve $\left.M_{1}\right)$ ve su düzeylerinden $\left(l_{1}, I_{2}\right.$ ve $\left.I_{3}\right)$ oluşan muamelenin verim üzerindeki etkisi tüm konularda anlamlı $(P<0.05)$ olduğu ve beş farklı grup oluşturduğu tespit edilmiştir (Çizelge 5). Ancak, gerek mikorizası gerekse mikorizalı sulama uygulamalarında, sulama suyunun miktarı arttıkça, verimlerininde arttığı görülmüştür. Suyun çok önemli ve çarpan faktörünün çok güçlü olduğu anlaşılmıştır. Mikoriza muamelesi ve en yüksek suyun en fazla kullanıldığı $\left(\mathrm{M}-\mathrm{I}_{3}\right)$ konuda 33.66 t ha${ }^{1}$ verim elde edilmiş ve ilk grubu oluşturmuştur. En düşük verim açık ara mikorizanın ve en düşük suyun uygulandığı konuda $\left(\mathrm{M}_{0}-\mathrm{I}_{1}\right) 20.54 \mathrm{t} \mathrm{ha}^{-1}$ alınmış ve son grubu oluşturduğu belirlenmiştir. Diğer konulardaki verim değerleri bu iki konuya ait değerlerin arasında kalmıştır. Sera koşullarında kısıntılı sulama programı ile yetiştirilen hıyar bitkisinden 0.138-133.995 $\mathrm{t} \mathrm{ha}^{-1}$ arasında verim alınmıştır (Mao ve ark., 2003). Mikoriza uygulanan çalışma ile alınan verim sonuçları bildirilen sonuçların sınırları arasında belirlenmiştir. Hıyar bitkisine ait parametreler; mikoriza uygulamasının yapılmadığı $\left(M_{0}\right)$ ancak suyun farklı düzeylerinin uygulandığı $\left(I_{1} ; I_{2}\right.$; ve $\left.I_{3}\right)$ konular ile mikoriza ve su düzeyleri arasında interaksiyonun $(\mathrm{P}<0.05)$ anlamlı olduğu, buna karşın mikoriza uygulanmamış konunun ise anlam düzeyinin daha zayıf $P<0.01$ ) bulunduğu görülmüştür. Mikorizasız $\left(M_{0}\right)$ ve mikorizalı (M) olan her iki konuya aynı miktarda sulama suyu uygulanmasına karşın, mikoriza uygulamasının gerek köklerde ve gerekse bitki vejetasyon kütlesinde pozitif etki yaratmış olabileceği düşünüldüğünde ve fenolojik olarak gözlemlenmiş hıyar veriminde, ciddi artışlar sağladığı elde edilen hasat değerlerinden saptanmıştır. Çalışmada, mevsimlik bitki su tüketimi ve sulama suyunun verim ile arasında pozitif doğrusal bir ilişki olduğu belirlenmiştir (Şekil 1).

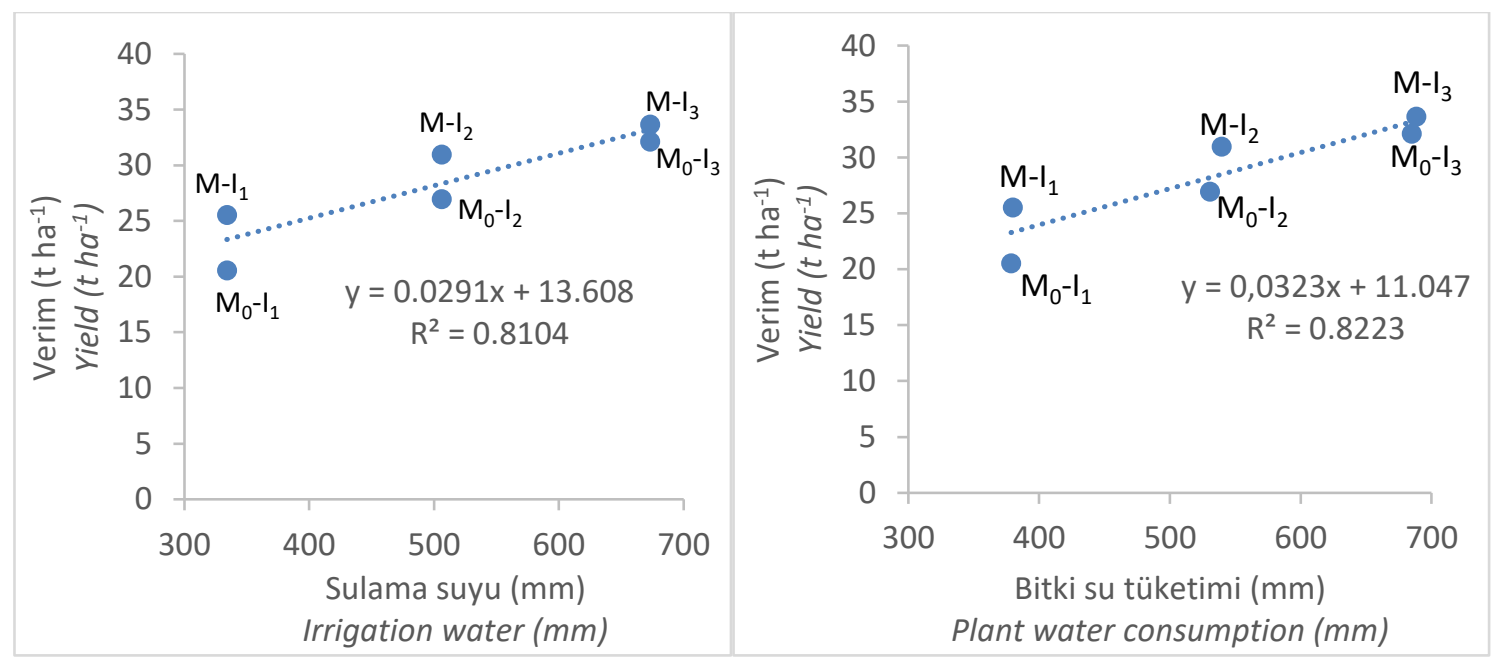

Şekil 1. Bitki su tüketimi ve sulama suyunun verim arasındaki ilişki

Figure 1. Relationship between plant water consumption and irrigation water yield 
Söz konusu regresyon eşitliğinde $R^{2}$ değeri sulama suyundan 0.81, mevsimlik bitki su tüketimde 0.82 çıkmıştır. Bu sonuca göre, verim ile mevsimlik bitki su tüketimi ve sulama suyu miktarı arasında kuvvetli bir ilişki olduğu söylenebilir. Sera koşullarında yapılan çalışmada hıyar bitkisinin mevsimlik bitki su tüketimi ile verim arasındaki ilişki 0.95 bulunmuştur (AlOmran ve Louki, 2011).

Çizelge 4. Hıyar bitkisinde verim, meyve çapı, meyve boyu ve meyve ağırlı̆ı̆na ait varyans analiz sonuçları Table 4. Variance analysis results of yield, fruit diameter, fruit length and fruit weight in cucumber plant

\begin{tabular}{|c|c|c|c|c|c|c|c|c|c|}
\hline \multirow[t]{3}{*}{$\begin{array}{l}\text { Konular } \\
\text { Treatments }\end{array}$} & \multirow[t]{3}{*}{ SD } & \multicolumn{2}{|c|}{$\begin{array}{l}\text { Verim }\left(\mathrm{t} \mathrm{ha}^{-1}\right) \\
\text { Yield }\left(\mathrm{tha}^{-1}\right)\end{array}$} & \multicolumn{2}{|c|}{$\begin{array}{c}\text { Meyve çapı }(\mathrm{mm}) \\
\text { Fruit diameter }(\mathrm{mm})\end{array}$} & \multicolumn{2}{|c|}{$\begin{array}{l}\text { Meyve boyu }(\mathrm{mm}) \\
\text { Fruit length }(\mathrm{mm})\end{array}$} & \multicolumn{2}{|c|}{$\begin{array}{l}\text { Meyve ağrılığı (g) } \\
\text { Fruit weight (g) }\end{array}$} \\
\hline & & KO & $\mathrm{F}$ & KO & $\mathrm{F}$ & KO & $\mathrm{F}$ & KO & $\mathrm{F}$ \\
\hline & & KO & $F$ & KO & $F$ & KO & $F$ & KO & $F$ \\
\hline $\begin{array}{l}\text { Tekerrür } \\
\text { Replicate }\end{array}$ & 2 & 0.25 & $0.10^{\text {ns }}$ & 0.828 & $0.972^{\mathrm{ns}}$ & 1.74 & $0.57^{\mathrm{ns}}$ & 0.87 & $0.31^{\mathrm{ns}}$ \\
\hline A & 1 & 55.65 & $22.61^{*}$ & 24.523 & $28.805^{*}$ & 84.54 & $27.70^{*}$ & 342.70 & $122.87^{*}$ \\
\hline Hata1 & 2 & 2.46 & & 0.851 & & 3.04 & & 2.79 & \\
\hline \multicolumn{10}{|l|}{ Error1 } \\
\hline B & 2 & 147.85 & $479.70 * *$ & 39.119 & $399.931 * *$ & 838.70 & $465.70 * *$ & 687.23 & $224.39 * *$ \\
\hline$A * B$ & 2 & 4.72 & $15.32^{* *}$ & 0.901 & $9.211^{* *}$ & 10.60 & $5.88^{*}$ & 114.27 & $37.31 * *$ \\
\hline Hata2 & 8 & 0.31 & & 0.098 & & 1.80 & & 3.06 & \\
\hline Error2 & & & & & & & & & \\
\hline $\begin{array}{l}\text { Genel } \\
\text { General }\end{array}$ & 17 & 211.24 & & 66.32 & & 940.42 & & 1150.92 & \\
\hline
\end{tabular}

SD: Serbestlik derecesi, ns: Önemsiz, *: \%5 seviyesinde önemli, **: \%1 seviyesinde önemli,

SD: Degree of freedom, ns: not significant, *: Significant at 5\%, **: Significant at 1\%

Meyve çapı, meyve boyu ve meyve ağırlıkları konularının tümünde tekerrürlerin etkisinin önemsiz ( $P>0.01)$, ancak mikoriza ve sulama uygulamalarının sırasıyla tüm konularda en az $(P<0.05)$ ve $(P<0.01)$ seviyesinde önemli olduğu hesaplanmıştır. Benzer tepkiler mikoriza ve sulama seviyeleri interaksiyonun; verim ve meyve çapı verilerinde istatistiksel olarak farklılık göstermiş $(P<0.01)$, meyve boyu ve meyve ağırlığındaki farklılık $(P<0.05)$ saptanmıştır (Çizelge 4). Kalite parametrelerinin tümünde de aynı etkinin oluştuğu ve özellikle sulama suyunun etkisinin önemli $(P<0.01)$ olduğu ifade edilebilir.

Çizelge 5. Hıyar bitkisinde verim, meyve çapı, meyve boyu ve meyve ağırlığının TUKEY gruplandırma sonuçları Table 5. Tukey grouping results of yield, fruit diameter, fruit length and fruit weight in cucumber

\begin{tabular}{ccccc}
\hline $\begin{array}{c}\text { Konu } \\
\text { Treatment }\end{array}$ & $\begin{array}{c}\text { Verim } \\
\text { Yield } \\
\left(\mathrm{t} \mathrm{ha}{ }^{-1}\right)\end{array}$ & $\begin{array}{c}\text { Meyve çapı }(\mathrm{mm}) \\
\text { Fruit diameter }(\mathrm{mm})\end{array}$ & $\begin{array}{c}\text { Meyve boyu (mm) } \\
\text { Fruit length }(\mathrm{mm}\end{array}$ & $\begin{array}{c}\text { Meyve ağırlı̆̆ (g) } \\
\text { Fruit weight }(\mathrm{g})\end{array}$ \\
\hline $\mathrm{M}_{0}-\mathrm{I}_{1}$ & $20.54 \mathrm{~d} \pm 1.10$ & $29 \mathrm{~d} \pm 0.95$ & $134 \mathrm{~d} \pm 2.96$ & $103 \mathrm{~d} \pm 2.85$ \\
$\mathrm{M}_{0}-\mathrm{I}_{2}$ & $26.94 \mathrm{c} \pm 0.65$ & $33 \mathrm{c} \pm 0.47$ & $149 \mathrm{c} \pm 0.50$ & $125 \mathrm{c} \pm 1.87$ \\
$\mathrm{M}_{0}-\mathrm{I}_{3}$ & $32.12 \mathrm{ab} \pm 0.97$ & $35 \mathrm{~b} \pm 0.66$ & $159 \mathrm{ab} \pm 0.50$ & $132 \mathrm{ab} \pm 0.91$ \\
$\mathrm{M}-\mathrm{I}_{1}$ & $25.52 \mathrm{c} \pm 0.74$ & $32 \mathrm{c} \pm 0.61$ & $139 \mathrm{~d} \pm 1.22$ & $122 \mathrm{c} \pm 1.53$ \\
$\mathrm{M}-\mathrm{I}_{2}$ & $30.96 \mathrm{~b} \pm 0.68$ & $35 \mathrm{~b} \pm 0.24$ & $156 \mathrm{~b} \pm 0.78$ & $130 \mathrm{~b} \pm 0.83$ \\
$\mathrm{M}-\mathrm{I}_{3}$ & $33.66 \mathrm{a} \pm 0.61$ & $37 \mathrm{a} \pm 0.31$ & $161 \mathrm{a} \pm 0.80$ & $135 \mathrm{a} \pm 0.68$ \\
\hline
\end{tabular}

Güz döneminde yetiştiriciliği yapılan hıyar bitkisinin ortalama meyve çapı 29-37 mm arasında değişmiş, en yüksek meyve çapı $\mathrm{M}-\mathrm{I}_{3}$ konusundan $37 \mathrm{~mm}$ alınırken en düşük $\mathrm{Mo}_{0} \mathrm{I}_{1}$ konusunda $29 \mathrm{~mm}$ ölçülmüştür. Meyve çapı üzerindeki etki incelendiğinde, aynı sulama suyu miktarının ( $I_{1}$ : \%66) uygulandığı, mikoriza uygulamasının yapıldığı konu (M) ile uygulamanın yapılmadığı konu $\left(\mathrm{M}_{0}\right)$ arasında yaklaşık $3 \mathrm{~mm}$ fark olduğu, bu farklılı̆ın mikoriza'nın etkisinden kaynaklanabileceği düşünülebilir ve hıyar meyve sınıflandırması üzerinde anlamlı etki yaptığı söylenebilir. Ancak, mikoriza uygulaması yapılan bitkilerde, fazla suyun meyve çapında aşırı büyümeye ve meyvede kalitenin düşmesine neden olmuştur (Çizelge 5). En düşük meyve boyu 
$\mathrm{M}_{0}-\mathrm{I}_{1}$ konusunda $134 \mathrm{~mm}$ elde edilirken en yüksek meyve boyu ise $\mathrm{M}-\mathrm{I}_{3}$ konuda $161 \mathrm{~mm}$ şeklinde elde edilmiştir. Farklı sulama suyu seviyelerinin uygulandığı araştırmada meyve boyunun 150$159.5 \mathrm{~mm}$ arasında saptanmıştır (Şahin ve ark., 2015). Mikoriza uygulaması ile birlikte verilen fazla suyun meyve boyunda fark oluşturduğu saptanmıştır. Araştırmada ölçümü yapılan meyve ağırlığı en düşük $M_{0}$ - $_{1}$ konusunda $103 \mathrm{~g}$, en yüksek ise $\mathrm{M}-\mathrm{I}_{3}$ 'de $135 \mathrm{~g}$ elde edilmiştir. Sera koşullarında yapılan bir çalışmada ise meyve ağırlığı 103.7-145.6 g arasında elde edilmiştir (Mamun Hossain ve ark., 2018). Araştırma süresince değerlendirmeye alınan meyve çapı, meyve boyu ve meyve ağırlığı parametrelerinde sulama suyu miktarının artışına bağlı olarak optimum seviyelere ulaştığı anlaşılmıştır. Ancak, sulama suyu miktarının artışının yanında mikoriza uygulamasının yapılması ile daha fazla güçlü ve iddialı sonuçlar alındığı saptanmıştır. Mikoriza uygulamasının bitkideki kök uzamasına sebep olduğundan dolayı kalite parametrelerinin, mikoriza uygulamasının yapılmadığı $\left(\mathrm{M}_{0}\right)$ konuya göre daha iyi sonuçlar verdiği, meyve çapı, meyve boyu ve meyve ağırlığında en iyi etkinin kısıtlı sulama suyu miktarı ile mikoriza uygulamasının yapıldığı konudan mikoriza uygulaması yapılmayan konuya göre ortalama \%10-20 arasında artışın olduğu, en bariz etkinin ise intiyacının \%66'sının karşılandığı sulama suyu miktarı ile birlikte mikoriza'nın uygulandığı konuda gerçekleştiği ve ikinci grubu oluşturduğu saptanmıştır.

\section{Sonuç ve Öneriler}

Güz döneminde mikoriza uygulaması yapılarak farklı sulama suyu seviyesi altında yetiştirilen hıyar bitkisinde sulama suyu miktarları, çalışmanın yarı-kurak iklim bölgesinde olmasına ve güz döneminde (ağustos-ekim) olmasına rağmen 334$673 \mathrm{~mm}$ arasında değişmiştir. Sulamaların damla sulama yöntemi ile yapılmasından dolayı yüzey akış ve derine sızma kayıpları gerçekleşmemiştir. $\mathrm{Bu}$ nedenle, uygulanan sulama suyu miktarı ile mevsimlik bitki su tüketimi arasında önemli farklılık saptanmamış, hıyar bitkisi için mevsimlik su tüketimi 378.59-688.45 mm arasında değiştiği tespit edilmiştir. Hesaplanan IWUE ve WUE değerleri 4.77-7.64 $\mathrm{kg} \mathrm{m}^{-3}$ ve 4.69-6.72 $\mathrm{kg} \mathrm{m}^{-3}$ arasında olduğu hesaplanmıştır. Mikoriza ve su düzeylerinden oluşan muamelenin tüm konulardaki verim değerleri 20.54-33.66 $\mathrm{t} \mathrm{ha}^{-1}$ arasında değişmiş ve bu uygulamaların diğer verim bileşenleri üzerinde de ciddi anlamda istatistiksel olarak farklı tepki vermiştir. Araştırma sonucunda birim alandan daha fazla verim alınması hususunda hıyar yetiştiriciliği yapılan alanlarda bitki köklerine mikoriza uygulaması, bitki köklerinin daha iyi gelişmesi ve etkin kök bölgesinde bulunan sudan daha fazla yararlanarak verimde önemli kazançlar elde edildiği söylenebilir. Suyun kısıtlı olduğu durumlarda da mikoriza uygulamasının yapılması verimde ciddi artışlara neden olmuştur. Çünkü, optimum su ihtiyacının $2 / 3$ 'ünün karşılandığı durumlarda mikoriza uygulaması ile verimde \%25 daha fazla ürün alınabileceği görülebilir. Sonuç olarak, hıyar bitkisi yetiştiriciliğinde birim alandan daha fazla ürün alma konusunda kök geliştirme özelliği nedeniyle bitki köklerine mikoriza uygulamasının yapılması ve optimum su ihtiyacının karşılanması önerilebilir.

\section{Çıkar Çatışması Beyanı: Makale yazarları} aralarında herhangi bir çıkar çatışması olmadığını beyan ederler.

\section{Kaynaklar}

Abd El-Mageed, T. A., Semida, W. M., Taha, R. S. ve Rady, M. M. (2018). Effect of summer-fall deficit irrigation on morpho-physiological, anatomical responses, fruit yield and water use efficiency of cucumber under salt affected soil. Scientia Horticulturae, 237, 148155.

Al-Karaki, G. N. (2006). Nursery inoculation of tomato with arbuscular mycorrhizal fungi and subsequent performance under irrigation with saline water. Scientia Horticulturae, 109(1), 1-7.

Al-Karaki, G. N. ve Al-Raddad, A. (1997). Effects of arbuscular mycorrhizal fungi and drought stress on growth and nutrient uptake of two wheat genotypes differing in drought resistance. Mycorrhiza, 7(2), 8388.

Al-Omran A. M. ve Louki, I. I. (2011). Yield response of cucumber to deficit irrigation in greenhouses. WIT 
Transactions on Ecology and the Environment, Vol 145. ISSN 1743-3541. doi: 10.2495/WRM110451

Anonim, (2017a). Sulama Çalışma Grubu Çalışma Belgesi. 2.Ormancılık ve Su Şurası, 5-7 Mayıs 2017, Afyon.

Anonim,

http://www.tuik.gov.tr/PreTablo.do?alt_id=1001

(Erişim tarihi: 12.11.2017)

Anonim, (2018). Şanlıurfa Meteoroloji Bölge Müdürlüğü, T.C. Tarım ve Orman Bakanlığı, Şanlıurfa.

Anonim, (2019). http://haseltarim.com/easternseeds/hiyar/ (Erişim tarihi: 22.10.2019)

Dhillon, N. P. S., Monforte, A. J., Pitrat, M., Pandey, S., Singh, P. K., Reitsma, K. R., ... McCreight, J. M. (2012). Melon Landraces of India: Contributions and Importance. Plant Breeding Reviews, 35, 85-150.

Dinç, U., Şenol, S., Sayın, M., Kapur, S., Güzel, N., Derici, R., ... Kara, E. E. (1988). Güneydoğu Anadolu Bölgesi Toprakları. (GAT): I. Harran Ovası. TÜBITAK Tarım ve Ormancılık Araştırma Grubu Güdümlü Araştırma Projesi Kesin Raporu. Proje No: TOAG-534, Adana.

Doorenbos, J. ve Pruitt, W.O. (1977) Crop Water Requirements. FAO Irrigation and Drainage Paper 24, FAO, Rome, (p 144).

Evelin, H., Kapoor, R. ve Giri, B. (2009). Arbuscular mycorrhizal fungi in alleviation of salt stress: a Review. Ann Bot., 104, 1263-80.

Howell, T. A., Cuenca, R. H., Solomon, K. H. (1990). Crop yield response. Manamegent of farm irrigation systems. (ed Hoffman et al.). ASAE, $312 \mathrm{~s}$.

James, D. W., Hanks, R. J. ve Jurinak., J. J. (1982). Modern irrigated soils. Published by John Wiley and Sons Inc. New York USA.

Jones, H. G. ve Corlett, J. E. (1992). Current topics in drought physiology. Journal of Agricultural Science, 119, 291296.

Kırnak, H. ve Demirtaş, M. N. (2006). Effects of different irrigation regimes and mulches on yield and macro nutrition levels of drip irrigated cucumber under upon filed conditions. Journal of Plant Nutrition, 29(9), 1675-1690.

Kramer, P. J. ve Boyer, J. S. (1995). Water relations of plants and soils. Academic Press, San Diego.

Lambers, H., Chapin, F. S. ve Pons, T. L. (2008). Plant Physiological Ecology. 2nd ed. New York: Springer. doi: 10.1007/978-0-387-78341-3
Lizana, C., Wentworth, M., Martinez, J. P., Villegas, D., Meneses, R., Murchie, E. H., ... Pinto, M. (2006). Differential adaptation of two varieties of common bean to abiotic stress I. Effects of drought on yield and photosynthesis. Journal of Experimental Botany, 57(3), 685-697.

Mamun Hossain, S. A., Wang, L. X. ve Liu, H. S. (2018). Improved greenhouse cucumber production under deficit water and fertilization in Northern China. Int $J$ Agric\&Biol Eng., 11(4), 58-64.

Mao, X., Liu, M., Wang, X., Liu, C., Hou, Z. ve Shi, J. (2003). Effects of deficit irrigation on yield and water use of greenhouse grown cucumber in the North China Plain. Agric. Water Manage., 61, 219-228.

Marschner, H. ve Dell, B. (1994). Nutrient uptake in mycorrhizal symbiosis. Plant Soil, 159(1), 89-102.

Ment, D., Shikano, I. ve Glazer, I. (2017). AbioticFactors. In: Hajek AE, Shapiro-Ilan DI (eds) Ecol. Invertebr. Dis. Wiley, Ltd, Hoboken, pp: 143-186.

Miransari, M. (2010). Contribution of arbuscular mycorrhizal symbiosis to plant growth under different types of soil stress. Plant Biol., 12, 563-9.

Nadeem, S. M., Ahmad, M., Zahir, A. Z., Javaid, A. ve Ashraf, M. (2014). The role of mycorrhizae and plant growth promoting rhizobacteria (PGPR) in improving crop productivity under stressful environmens. Bio technol. Adv., 32, 429-448.

Şahin, U., Kuslu, Y. ve Kiziloglu, F. M. (2015). Response of cucumbers to different irrigation regimes applied through drip-irrigation system. Journal of Animal and Plant Sciences, 25(1), 198-205.

Şimşek, M., Tonkaz, T., Kaçıra, M., Çömlekçioğlu, N. ve Doğan, Z. (2005). The effects of different irrigation regimes on cucumber (Cucumis sativus L.) yield and yield characteristics under open field conditions. Agric. Water Manage., 73(3), 173-191.

Wang, W., Vinocur, B. ve Altman, A. (2003). Plant responses to drought, salinity and extreme temperatures: towards genetic engineering for stress tolerance. Planta, 218, 1-14.

Zhang, X., Qina, W., Chena, S., Shaoa, L. ve Suna, H. (2017). Responses of yield and WUE of winter wheat to water stress during the past three decades-A case study in the North China Plain. Agric. Water Manage., 179, 47-54. 